\title{
Assesment of the quality of information patients on treatment of keratoconus on YouTube
}

asli cetinkaya yaprak ( $\square$ aslickaya@yahoo.com )

Akdeniz Universitesi Tip Fakultesi https://orcid.org/0000-0002-4285-419X

Çisil Erkan Pota

Akdeniz Universitesi Tip Fakultesi

\section{Research Article}

Keywords: DISCERN score, Global Quality score, Journal of the American Medical Association score, Keratoconus, YouTube

Posted Date: September 10th, 2021

DOl: https://doi.org/10.21203/rs.3.rs-883166/v1

License: (1) This work is licensed under a Creative Commons Attribution 4.0 International License. Read Full License 


\section{Abstract \\ Purpose}

To evaluate the reliability, quality and effectiveness of YouTube videos adressing treatment of keratoconus.

\section{Methods}

This is a retrospective, cross-sectional and register-based study. A YouTube search was performed using the keyword treatment of keratoconus and the first 100 videos that came out were included in the study. The numbers of views, likes, dislikes, comments, daily viewing rate (number of views per day), uploaded source (physicians, public or private institution, health channel or patients), country of origin, video type (patient experience, scholarly information), and describe treatment technique (contact lens, corneal crosslinking, intrastromal corneal ring, topography guided-photorefractive keratectomy, keratoplasty) were evaluated for all videos. They were also evaluated regarding their DISCERN, Journal of the American Medical Association (JAMA), global quality (GQS) and usefulness scores by two independent ophthalmologists.

\section{Results}

Of the top 100 videos, 83 videos met the criteria. The mean DISCERN, JAMA, GQS and usefulness score were $42.92 \pm 18.14,2.7 \pm 0.73,3.07 \pm 1.25$ and $2.99 \pm 1.44$, respectively. Of the 83 videos, $35(42.2 \%)$ had been uploaded by physicians, $19(22.9 \%)$ by patients, $15(18.1 \%)$ by health channel and $14(16.9 \%)$ by institutions/private health institutions. In the correlation analysis, the four scoring systems showed a statistically significant and strong positive correlation with each other $(p<0.001)$. In addition, viewing rate DISCERN, GQS, usefulness scores, number of likes, dislikes and comments showed a statistically significant positive correlation.

\section{Conclusion}

The content of YouTube videos regarding treatment of keratoconus is of generally good quality and is educational for patients. Increasing the number of videos uploaded by healthcare professionals will increase the quality, reliability and informative features of the videos.

\section{Introduction}

Keratoconus is a non-inflammatory condition characterized by progressive corneal thinning and irregular astigmatism resulting from corneal protrusion with unknown etiology $[1,2]$. It presents in the period of 
adolescence or early adulthood and can progress until the third and fourth decades [3]. It's incidence in the general population has been reported between 50 and 230 per 100,000 (approximately 1 per 2000) [4]. These differences in prevalence rates are due to ethnicity and environmental factors such as the use of contact lenses, UV exposure and eye rubbing, etc [5-10]. In the beginning period of the disease, vision loss due to changes in corneal refractive power can be corrected with the help of glasses. As the astigmatism becomes increasingly irregular, contact lenses are started to be used. These treatments cause patients to have better vision but do not affect the progression of the disease. Collagen crosslinking, topography guided-photorefractive keratectomy or intrastromal corneal ring segment treatment methods are applied to reduce and/or stop progression in keratoconus patients [11]. Although the decrease in the progression of the disease reduces the need for corneal transplantation, $12-20 \%$ of patients undergo corneal transplantation [12].

The use of social media for research and information purposes are becoming more common day by day. Keratoconus is especially diagnosed during adolescence or early adulthood; social media usage rates in this age group in the USA have been reported as 77\% [13]. Considering the global incidence of keratoconus, a population that cannot be ignored is emerging that uses social media to explore treatment options. YouTube, which provides free video sharing over the internet, ranks second among the most used websites worldwide [14]. YouTube is used by patients, relatives and physicians to access health information and is becoming an increasingly popular option. Everyone can easily access YouTube videos, but these videos are not evaluated before they are published. Therefore, it is important to conduct research to evaluate the reliability and accuracy of this information [15]. In particular, false information that may be given in treatment options may cause patients to be prejudiced against treatments and may affect the trust bond between the patient and the doctor [16].

There are many videos on YouTube covering diseases and their treatments. As far as we know, there is no study yet on the content and quality of videos related to treatment of keratoconus. Therefore, in this study, we aimed to evaluate the effectiveness, quality, reliability, and popularity of videos on the treatment of keratoconus.

\section{Materials And Methods}

This study used only observational and publicly available data, therefore exempt from ethics committee approval. Our retrospective, cross-sectional and register-based study was searched by typing the phrase 'treatment of keratoconus' in the YouTube (http://www.youtube.com) search bar on May 25, 2021. Search for videos were performed after clearing all watch history and without user login. The standard search preference was selected as 'sort videos by relevance'. All videos that appeared after typing the keyword were viewed and the first 100 videos were evaluated. Since the rate of access to videos after the first five pages (each with 20 videos per page) decreased significantly, we did not include more than fifth page in the scope of the study [17]. 
All videos were watched by two ophthalmologists (A.Ç.Y. and Ç.E.P.); evaluations and scores were recorded double-blindly. Videos in English and related to treatment of keratoconus were included in the study. Advertisement, non-English videos, silent videos, videos shorter than 30 seconds, repetitive videos and videos without the like, dislike or comments function were excluded from the study. All videos meeting the study inclusion criteria were recorded for further evaluation.

Views for all videos, time since upload (until May 25, 2021), likes, dislikes, comments, daily viewing rate (number of views per day), duration, uploaded source (physicians, public or private institution, health channel or patients), country of origin, video type (patient experience, scholarly information), and treatment technique (contact lens, corneal crosslinking, intrastromal corneal ring, topography guided-photorefractive keratectomy, keratoplasty) were evaluated. In addition, viewer interaction (number of likes - number of dislikes) / total number of view x 100 was calculated. All videos were also evaluated regarding their DISCERN, Journal of the American Medical Association (JAMA), global quality (GQS) and usefulness scores.

The DISCERN scoring system is shown in Supplemental Table 1. It contains a total of 16 questions consisting of 3 parts, each scored from 1 to 5 . A minimum of 16 points and a maximum of 75 points can be obtained; and is classified in five groups as excellent (ie, 63-75 points), good (ie, 51-62 points), fair (ie, 39-50 points), poor (ie, 27-38 points), or very poor (ie, 16-26 points) [18].

The JAMA scoring system is shown in Supplemental Table 2. JAMA is a well-known scoring system used to demonstrate the reliability of online health resources. Scoring from 0 to 1 is made for four criteria (authorship, attribution, disclosure, and currency). A maximum of 4 points can be obtained and 4 points indicate the highest quality. GQS is shown in Supplemental Table 2. This scoring system evaluates how educational the videos are for patients, the information flow in the videos, their ease of use and quality. A total of 5 questions are scored from 0 to 1 , and 5 indicates excellent quality.

Video usefulness score is shown in Supplemental Table 2 and was calculated based on the following criteria: definition, indication, procedure involved, complication, and prognosis-survival. Similarly, the effectiveness of this system video content, which was scored from 0 to 1 , in providing information was evaluated. The best correct information about the disease is scored as $4-5$ points (Total score: $0,1=$ not useful; $2,3=$ useful; $4,5=$ very useful).

\section{Statistical Analysis}

Statistical analysis was performed using IBM SPSS, version 23.0 (SPSS Inc., IL-USA) software. To define the sample, continuous variables were expressed as mean \pm standard deviation and median (minimummaximum) values and categorical variables as numbers and percentages. Normality was tested using the Kolmogorov-Smirnov test. In the comparison of the continuous data, the Mann-Whitney $U$ test was applied to the non-normally distributed data and the independent-samples $t$ test was used for the data with normal distribution. For the analysis of correlation, Spearman correlation coefficient test was used. The results were evaluated at the $95 \%$ confidence interval, and a $p$ value of $<0.05$ was considered 
statistically significant. The kappa coefficient was used to evaluate the agreement between two independent reviewers. All numerical data are given by averaging the ratings of two independent reviewers.

\section{Results}

Of the top 100 videos, 83 videos met the criteria and were included in the study. Fifteen of the videos were excluded because they were not in English and 2 were duplicate videos. Table 1 shows the descriptive statistics of the 83 videos.

When we look at the origins of the countries where 83 videos were uploaded; 61 (73.5\%) videos were uploaded from USA, 8 (9.6\%) videos from India, 6 (7.2\%) videos from England, 2 (2.4\%) videos from Germany, 2 (2.4\%) videos from United Arab Emirates and 4 (4.8\%) videos uploaded from the other countries (Switzerland, Australia, Portugal, Philippines). When we look at the upload sources, 35 (42.2\%) videos had been uploaded by physicians, 19 (22.9\%) videos by patients, $15(18.1 \%)$ videos by health channel and $14(16.9 \%)$ videos by institutions/private health institutions. While $47(56.6 \%)$ videos were for information purposes, 24 (28.9\%) videos were related to patient experiences and 12 (14.5\%) videos were for educational purposes. Of the videos, 20 (24.09\%) videos mentioned about crosslinking, 8 (9.63\%) videos intrastromal corneal ring, 7 videos (8.43\%) contact lenses, 6 (7.22\%) videos keratoplasty, 2 (2.4\%) videos topography guided-photorefractive keratectomy, $12(14.45 \%)$ videos mentioned 3 or more treatment modalities; 28 videos (33.73\%) did not mention any treatment method.

There was a significant level of agreement between the two commentators evaluating the videos. The agreement power among the commentators was found to be $92.3 \%$ (kappa score:0.923). As shown in Table 2, when we compare them according to the sources, views, video age, likes, dislikes, DISCERN, JAMA, GQS and usefulness score were found to be statistically different $(p<0.05)$. No statistically significant difference was observed in views ratio and comments.

The correlation analysis between the parameters of the videos and the scoring systems is shown in Table 3. We found that the four scoring systems showed a statistically significant and strong positive correlation with each other $(p<0.001)$. We also saw that there was a statistically significant positive correlation with viewing rate DISCERN, GQS, usefulness scores, number of likes, dislikes and comments. Similarly, we found that video length showed a statistically significant and strong positive correlation with all scoring systems, number of likes, dislikes and comments.

\section{Discussion}

With the increase in the use of the internet and social media in recent years, patients have started to prefer to use online resources instead of consulting their physicians to get information about their personal health status [19]. The variability and irregularity of online information quality can lead to misdirection of patients and negatively affect the clinician-patient relationship. Therefore, it is important 
for clinicians to be aware of the content and quality of online information. YouTube has been constantly updating its content for 14 years; it' s use and popularity is increasing day by day for obtaining information because it is easily accessible, free and independent [20]. In the literature, there are many studies evaluating the content and quality of YouTube videos in recent years. There is no study in the literature examining the quality and reliability of the information provided by YouTube videos about treatment of keratoconus.

Keratoconus usually affects people in adolescence and early adulthood. Therefore, YouTube is an important source of information for this specific disease that affects the age group that uses the internet the most. In our study, when we look at the sources that upload the videos, we see that $60.3 \%$ are uploaded by health professionals and $22.9 \%$ are uploaded by patients. Compared to the previous studies, the abundance of videos uploaded by healthcare professionals ensures that video content is of higher quality and reliability $[20,21]$.

In previous studies many different scoring system was used to assess the quality and reliability of videos $[22,23]$. In our study, we used DISCERN, JAMA, GQS and usefulness scoring systems and the mean values of which were $42.92 \pm 18.14,2.7 \pm 0.73,3.07 \pm 1.25$ and $2.99 \pm 1.44$, respectively. These score values show that the treatment of keratoconus videos are of high quality. In a similar study by Kalayci et al. in which the keyword 'keratoplasty for patients' was used, the DISCERN, JAMA, GQS, and usefulness scores were reported as $42.11,1.82,2.35$, and 2.01 , respectively, and our results were slightly higher when compared to this study [21]. When we look at the results of the 26 videos uploaded by the physician and the data which was evaluated in the study of Kalayci et al., we see that the scores were similar to our study. We think that this difference may be due to the use of a more specific topic based on diagnosis as a keyword in our study.

In our study, when we examine the data separately according to the sources from which the videos were uploaded, we see that the DISCERN, JAMA, GQS and usefulness scores of the videos uploaded by physicians and institutions are significantly higher. This high score is also supported by previous studies $[24,25]$. However, in a study by Khatri et al., it was stated that the videos uploaded by the health channel uploaded in the local language are more popular than the videos uploaded by physicians and health institutions [26]. In our study, the values of the videos uploaded by the health channel are below the working average. Therefore, even if there is an inconsistency in the videos uploaded by the health channel in the literature, the videos uploaded by physicians and health institutions should be seen as quality information sources. In our study, the number of videos uploaded by healthcare professionals were high. In most of the similar studies, we see that there are many videos uploaded by nonphysicians $[16,20,21,27,28]$. It is important to motivate and encourage health professionals to upload videos to video sharing platforms in order for the audience to reach better quality and accurate information.

The number of views of the videos is an important parameter that shows the popularity of the videos [29]. Daily viewing rates are very valuable in showing the up-to-dateness of videos. However, the 
number of views and daily views can be easily manipulated by video uploaders. It has been suggested that the correlation analysis between daily viewing rates and likes, dislikes and comments can provide us with more objective data to guide us [30]. In our study, we found that there was a strong positive correlation between daily viewing rates and likes, dislikes and comments, supporting this view.

When we look at the origins of the countries where the videos were uploaded, we see that $73.5 \%$ were uploaded from the USA. It has been suggested that this high rate may be due to the fact that the selection of only videos in English has a great effect, as well as the use of social media platforms by private institutions in the USA health system to make themselves advantageous [20].

This study has certain limitations. First of all, using only English videos and evaluating all videos can make the results more objective, although the number of non-English videos is low. Second, YouTube is an interactive video sharing platform, so editing, deleting uploaded videos or uploading new videos may change the results. Third, the scoring system was not used to evaluate the image and sound quality of the videos. Finally, the results may vary depending on the software of the search keyword and the geographical region it is written in. Similarly, the search history of the searcher also affects the ranking of the videos. Despite all these limits, the examination of the videos by two different ophthalmologists and the statistically significant strong correlation between them makes the data valuable.

In conclusion, YouTube is an important platform that patients can use to get information about treatment of keratoconus. It is important to watch videos uploaded from reliable sources to avoid misleading information. Therefore, ophthalmologists should guide their patients who want to get information via YouTube to watch videos uploaded by health professionals.

\section{Declarations}

Funding The authors received no funding for the research, authorship and/or publication of this article from any government or private institution.

Data availability All data and material are available on request from the authors. The data that support the findings of this study are available from the corresponding author, [A.Ç.Y.], upon reasonable request.

\section{Compliance with ethical standards}

Conflict of interest The authors declare that they have no conflict of interest.

Ethical approval This study used only observational and publicly available data, therefore exempt from ethics committee approval.

\section{References}

1. Krachmer JH, Feder RS, Belin MW. Keratoconus and related noninflammatory corneal thinning disorders. Surv Ophthalmol 1984;28:293-322. https://doi.org/10.1016/0039-6257(84)90094-8. 
2. Rabinowitz YS. Keratoconus. Surv Ophthalmol 1998;42:297-319. https://doi.org/10.1016/s00396257(97)00119-7.

3. Godefrooij DA, Soeters N, Imhof SM, Wisse RP. Corneal Cross-Linking for Pediatric Keratoconus: Long-Term Results. Cornea. 2016;35:954-958. https://doi.org/10.1097/IC0.0000000000000819.

4. Ertan A, Muftuoglu 0 . Keratoconus clinical findings according to different age and gender groups. Cornea 2008;27:1109-1113. https://doi.org/10.1097/IC0.0b013e31817f815a.

5. Hashemi H, Beiranvand A, Khabazkhoob M, Asgari S, Emamian MH, Shariati M, Fotouhi A. Prevalence of keratoconus in a population-based study in Shahroud. Cornea. 2013;32:1441-1445. https://doi.org/10.1097/IC0.0b013e3182a0d014.

6. Jonas JB, Nangia V, Matin A, Kulkarni M, Bhojwani K. Prevalence and associations of keratoconus in rural maharashtra in central India: the central India eye and medical study. Am J Ophthalmol. 2009;148:760-765. https://doi.org/10.1016/j.ajo.2009.06.024.

7. Millodot M, Shneor E, Albou S, Atlani E, Gordon-Shaag A. Prevalence and associated factors of keratoconus in Jerusalem: a cross-sectional study. Ophthalmic Epidemiol. 2011;18:91-97. https://doi.org/10.3109/09286586.2011.560747.

8. Nielsen K, Hjortdal J, Aagaard Nohr E, Ehlers N. Incidence and prevalence of keratoconus in Denmark. Acta Ophthalmol Scand. 2007;85:890-892. https://doi.org/10.1111/j.1600-0420.2007.00981.x.

9. Jafri B, Lichter H. Stulting RD. Asymmetric keratoconus attributed to eye rubbing. Cornea 2004;23:560-564. https://doi.org/10.1097/01.ico.0000121711.58571.8d.

10. Davidson AE, Hayes S, Hardcastle AJ, Tuft SJ. The pathogenesis of keratoconus. Eye (Lond). 2014;28:189-195. https://doi.org/10.1038/eye.2013.278.

11. Shetty R, Kaweri L, Pahuja N, Nagaraja H, Wadia K, Jayadev C, Nuijts R, Arora V. Current review and a simplified "five-point management algorithm" for keratoconus. Indian J Ophthalmol. 2015;63:46-53. https://doi.org/10.4103/0301-4738.151468.

12. Mohammadpour M, Heidari Z, Hashemi H. Updates on Managements for Keratoconus. J Curr Ophthalmol. 2017;302:110-124. https://doi.org/10.1016/j.joco.2017.11.002.

13. Aslam S. YouTube by the numbers: stats, demographics \& fun facts: omnicore. 2021. https://www.omnicoreagency.com/youtube-statistics/ . Accessed July 1, 2021.

14. Erdem MN, Karaca S. Evaluating the Accuracy and Quality of the Information in Kyphosis Videos Shared on YouTube. Spine (Phila Pa 1976) 2018;43:E1334-E1339. doi:

10.1097/BRS.0000000000002691.

15. Singh SK, Liu S, Capasso R, Kern RC, Gouveia CJ. YouTube as a source of information for obstructive sleep apnea. Am J Otolaryngol. 2018;39:378-382. https://doi.org/10.1016/j.amjoto.2018.03.024.

16. Mangan MS, Cakir A, Yurttaser Ocak S, Tekcan H, Balci S, Ozcelik Kose A. Analysis of the quality, reliability, and popularity of information on strabismus on YouTube. Strabismus. 2020;28:175-180. https://doi.org/10.1080/09273972.2020.1836002. 
17. Morahan-Martin JM. How internet users find, evaluate, and use online health information: a crosscultural review. Cyberpsychol Behav 2004;7:497-510. https://doi.org/10.1089/cpb.2004.7.497.

18. Allam A, Schulz PJ, Krauthammer M. Toward automated assessment of health Web page quality using the DISCERN instrument. J Am Med Inform Assoc 2017;24:481-487. https://doi.org/10.1093/jamia/ocw140.

19. ReFaey K, Tripathi S, Yoon JW, Justice J, Kerezoudis P, Parney IF, Bendok BR, Chaichana KL, Quiñones-Hinojosa A. The reliability of YouTube videos in patients education for Glioblastoma Treatment. J Clin Neurosci. 2018;55:1-4. https://doi.org/10.1016/j.jocn.2018.07.001.

20. Erol MK, Kalayci M, Cetinkaya E, Suren E, Yigit K. Quality assessment of YouTube videos intended to inform patients about retinal detachment surgery. Health Policy Technol 2021;10:187190. https://doi.org/10.1016/j.hlpt.2020.10.002

21. Kalayci M, Cetinkaya E, Suren E, Yigit K, Erol MK. Are YouTube Videos Useful in Informing Patients about Keratoplasty? Semin Ophthalmol. 2021;22:1-6. https://doi.org/10.1080/08820538.2021.1890145.

22. Fat MJ, Doja A, Barrowman N, Sell E. YouTube videos as a teaching tool and patient resource for infantile spasms. J Child Neurol. 2011;26:804-809. https://doi.org/10.1177/0883073811402345.

23. Sood A, Sarangi S, Pandey A, Murugiah K. YouTube as a source of information on kidney stone disease. Urology. 2011;77:558-562. https://doi.org/10.1016/j.urology.2010.07.536.

24. Bora K, Das D, Barman B, Borah P. Are internet videos useful sources of information during global public health emergencies? A case study of YouTube videos during the 2015-16 Zika virus pandemic. Pathog Glob Health. 2018;112:320-328. https://doi.org/10.1080/20477724.2018.1507784.

25. Kocyigit BF, Akaltun MS, Sahin AR. YouTube as a source of information on COVID-19 and rheumatic disease link. Clin Rheumatol 2020;39:2049-2054. https://doi.org/10.1007/s10067-020-05176-3.

26. Khatri P, Singh SR, Belani NK, Yeong YL, Lohan R, Lim YW, Teo WZ. YouTube as source of information on 2019 novel coronavirus outbreak: a cross sectional study of English and Mandarin content. Travel Med Infect Dis. 2020;35:101636. https://doi.org/10.1016/j.tmaid.2020.101636.

27. Kuçuk B, Sirakaya E. An Analysis of YouTube Videos as Educational Resources for Patients About Refractive Surgery. Cornea 2020;394:491-494. https://doi.org/10.1097/IC0.0000000000002237.

28. Ozsoy-Unubol T, Alanbay-Yagci E. YouTube as a source of information on fibromyalgia. Int J Rheum Dis 2021;24:197-202. https://doi.org/10.1111/1756-185X.14043.

29. Gabarron E, Fernandez-Luque L, Armayones M, Lau AY. Identifying Measures Used for Assessing Quality of YouTube Videos with Patient Health Information: A Review of Current Literature. Interact J Med Res. 2013;2:e6. https://doi.org/10.2196/ijmr.2465.

30. Altunel O, Sirakaya E. Evaluation of YouTube videos as sources of information about multifocal intraocular lens. Semin Ophthalmol 2021;18:1-5. https://doi.org/10.1080/08820538.2021.1900281.

\section{Tables}




\begin{tabular}{|lll|}
\hline & Mean \pm SD & Range \\
\hline Views (n) & $15,765 \pm 37,720$ & $43-274,105$ \\
\hline Views ratio (daily) & $12.75 \pm 29.75$ & $0-208$ \\
\hline Video age (days) & $48.04 \pm 32.2$ & $1-136$ \\
\hline Likes (n) & $330 \pm 2,082$ & $0-19,000$ \\
\hline Dislikes (n) & $5,25 \pm 12.78$ & $0-93$ \\
\hline Comments (n) & $43.91 \pm 120.49$ & $0-903$ \\
\hline Length (minutes) & $8.46 \pm 16.65$ & $1-87$ \\
\hline Viewer interactions & $1.43 \pm 3.16$ & $0-28.71$ \\
\hline DISCERN score & $42.92 \pm 18.14$ & $16-80$ \\
\hline JAMA score & $2.7 \pm 0.73$ & $1-4$ \\
\hline Global Quality score & $3.07 \pm 1.25$ & $1-5$ \\
\hline Usefulness score & $2.99 \pm 1.44$ & $0-5$ \\
\hline
\end{tabular}

Table 1. Descriptive statistics of treatment of keratoconus videos

SD, Standard deviation; JAMA, Journal of the American Medical Association.

Table 2. The analysis of the videos according to uploader 


\begin{tabular}{|c|c|c|c|c|c|}
\hline & $\begin{array}{l}\text { Physicians } \\
(n=35)\end{array}$ & Institution $(n=15)$ & $\begin{array}{l}\text { Health } \\
\text { channel }(n=14)\end{array}$ & $\begin{array}{l}\text { Patients } \\
(n=19)\end{array}$ & $p$ \\
\hline Views (n) & $\begin{array}{l}21,936 \pm \\
52,650\end{array}$ & $15,223 \pm 19,145$ & $18,540 \pm 30,748$ & $\begin{array}{l}2,783 \pm \\
4,408\end{array}$ & 0.013 \\
\hline $\begin{array}{l}\text { Views ratio } \\
\text { (daily) }\end{array}$ & $20.74 \pm 43.02$ & $8.68 \pm 9.07$ & $9.2 \pm 15.75$ & $3.81 \pm 7.02$ & 0.056 \\
\hline $\begin{array}{l}\text { Video age } \\
\text { (days) }\end{array}$ & $37.86 \pm 30.05$ & $48.20 \pm 23.2$ & $66.86 \pm 32.91$ & $\begin{array}{l}52.79 \pm \\
36.26\end{array}$ & 0.02 \\
\hline Likes (n) & $674.37 \pm 3,199$ & $105.40 \pm 112.16$ & $99.21 \pm 131.63$ & $\begin{array}{l}43.32 \pm \\
79.52\end{array}$ & 0.02 \\
\hline Dislikes (n) & $7.51 \pm 18.45$ & $4.73 \pm 5.43$ & $6 \pm 7.9$ & $0.95 \pm 1.54$ & 0.038 \\
\hline Comments (n) & $\begin{array}{l}59.97 \pm \\
174.41\end{array}$ & $23.71 \pm 46.98$ & $44.92 \pm 57.59$ & $\begin{array}{l}29.37 \pm \\
55.83\end{array}$ & 0.64 \\
\hline $\begin{array}{l}\text { Viewer } \\
\text { interactions }\end{array}$ & $1.82 \pm 4.73$ & $1.33 \pm 1.32$ & $0.82 \pm 0.46$ & $1.23 \pm 1.09$ & 0.764 \\
\hline DISCERN score & $50.46 \pm 19.33$ & $51.93 \pm 16.02$ & $37.71 \pm 9.71$ & $\begin{array}{l}25.74 \pm \\
3.86\end{array}$ & $<0.001$ \\
\hline JAMA score & $2.77 \pm 0.77$ & $3.07 \pm 0.7$ & $2.64 \pm 0.5$ & $2.32 \pm 0.67$ & 0.016 \\
\hline $\begin{array}{l}\text { Global Quality } \\
\text { score }\end{array}$ & $3.63 \pm 1.19$ & $3.87 \pm 0.92$ & $2.43 \pm 0.85$ & $1.89 \pm 0.57$ & $<0.001$ \\
\hline $\begin{array}{l}\text { Usefulness } \\
\text { score }\end{array}$ & $3.54 \pm 1.5$ & $3.8 \pm 0.94$ & $2.79 \pm 0.89$ & $1.47 \pm 0.51$ & $<0.001$ \\
\hline
\end{tabular}

JAMA, Journal of the American Medical Association. 


\begin{tabular}{|c|c|c|c|c|c|c|c|}
\hline & Likes & Dislikes & Comments & $\begin{array}{l}\text { DISCERN } \\
\text { score }\end{array}$ & $\begin{array}{l}\text { JAMA } \\
\text { score }\end{array}$ & $\begin{array}{l}\text { Global } \\
\text { Quality } \\
\text { score }\end{array}$ & $\begin{array}{l}\text { Usefulness } \\
\text { score }\end{array}$ \\
\hline \multirow[t]{2}{*}{ Viewing ratio } & $\begin{array}{l}r= \\
0.925\end{array}$ & $\begin{array}{l}r= \\
0.839\end{array}$ & $r=0.705$ & $r=0.331$ & $\begin{array}{l}r= \\
-0.03\end{array}$ & $r=0.280$ & $r=0.297$ \\
\hline & $\begin{array}{l}p< \\
0.001\end{array}$ & $\begin{array}{l}p< \\
0.001\end{array}$ & $p<0.001$ & $p=0.02$ & $\begin{array}{l}p= \\
0.791\end{array}$ & $p=0.01$ & $p=0.006$ \\
\hline \multirow[t]{2}{*}{$\begin{array}{l}\text { Viewer } \\
\text { interaction }\end{array}$} & $\begin{array}{l}r= \\
0.15\end{array}$ & $\begin{array}{l}r= \\
-0.176\end{array}$ & $r=0.152$ & $r=0.239$ & $\begin{array}{l}r= \\
0.267\end{array}$ & $r=0.213$ & $r=0.189$ \\
\hline & $\begin{array}{l}p= \\
0.177\end{array}$ & $\begin{array}{l}p= \\
0.111\end{array}$ & $p=0.178$ & $p=0.03$ & $\begin{array}{l}p= \\
0.015\end{array}$ & $p=0.053$ & $p=0.087$ \\
\hline \multirow[t]{2}{*}{ Length } & $\begin{array}{l}r= \\
0.455\end{array}$ & $\begin{array}{l}r= \\
0.259\end{array}$ & $r=0.353$ & $r=0.667$ & $\begin{array}{l}r= \\
0.409\end{array}$ & $r=0.572$ & $r=0.64$ \\
\hline & $\begin{array}{l}p< \\
0.001\end{array}$ & $\begin{array}{l}p= \\
0.018\end{array}$ & $p=0.001$ & $p<0.001$ & $\begin{array}{l}p< \\
0.001\end{array}$ & $p<0.001$ & $p<0.001$ \\
\hline \multirow[t]{2}{*}{$\begin{array}{l}\text { DISCERN } \\
\text { score }\end{array}$} & $\begin{array}{l}r= \\
0.354\end{array}$ & $\begin{array}{l}r= \\
0.181\end{array}$ & $r=0.095$ & - & $\begin{array}{l}r= \\
0.556\end{array}$ & $r=0.894$ & $r=0.914$ \\
\hline & $\begin{array}{l}p= \\
0.001\end{array}$ & $\begin{array}{l}p= \\
0.102\end{array}$ & $p=0.4$ & - & $\begin{array}{l}p< \\
0.001\end{array}$ & $p<0.001$ & $p<0.001$ \\
\hline \multirow[t]{2}{*}{ JAMA score } & $\begin{array}{l}r= \\
0.066\end{array}$ & $\begin{array}{l}r= \\
-0.118\end{array}$ & $r=-0.018$ & - & - & $r=0.521$ & $r=0.501$ \\
\hline & $\begin{array}{l}p= \\
0.553\end{array}$ & $\begin{array}{l}p= \\
0.288\end{array}$ & $p=0.872$ & - & - & $p<0.001$ & $p<0.001$ \\
\hline \multirow[t]{2}{*}{$\begin{array}{l}\text { Global } \\
\text { Quality score }\end{array}$} & $\begin{array}{l}r= \\
0.267\end{array}$ & $\begin{array}{l}r= \\
0.092\end{array}$ & $r=-0017$ & - & - & - & $r=0.885$ \\
\hline & $\begin{array}{l}p=0 \\
015\end{array}$ & $\begin{array}{l}p= \\
0.407\end{array}$ & $p=0879$ & - & - & - & $p<0.001$ \\
\hline \multirow[t]{2}{*}{$\begin{array}{l}\text { Usefulness } \\
\text { score }\end{array}$} & $\begin{array}{l}r= \\
0.301\end{array}$ & $r=0.17$ & $r=0.083$ & - & - & - & - \\
\hline & $\begin{array}{l}p= \\
0.006\end{array}$ & $\begin{array}{l}p= \\
0.124\end{array}$ & $p=0.463$ & - & - & - & - \\
\hline
\end{tabular}

Table 3. The correlation between some video parameters and the scoring systems JAMA, Journal of the American Medical Association.

\section{Supplementary Files}

This is a list of supplementary files associated with this preprint. Click to download. 
- SupplementDigitalContent.docx

Page 13/13 